\title{
ANÁLISIS JURISPRUDENCIAL DEL BITCÓIN
}

\author{
Jurisprudential Analysis of The Bitcoin
}

\author{
Omar Ahomed Chávez \\ Universidad ESAN, Perú \\ https://orcid.org/0000-0002-4891-6670
}

\section{Resumen}

La investigación tiene como objetivo general analizar a través de la jurisprudencia comparada la postura estatal con respecto al tratamiento y la regulación de operaciones realizadas mediante la moneda digital bitcóin; en cuanto a los objetivos específicos, estos son identificar la política pública y el marco filosófico apropiado para el uso de esta moneda criptográfica.

Palabras claves: bitcóin, política pública, libertarismo, liberalismo y ordoliberalismo.

\section{Abstract}

The general objective of the research is to analyze through comparative jurisprudence, the state's position regarding the treatment and regulation of operations carried out using the digital currency of bitcoin; having as specific objectives to identify the public policy and the philosophical framework appropriate to this cryptographic currency.

Keywords: bitcoin, public policy, libertarianism, liberalism and ordoliberalism. 


\section{Introducción}

Cuando era estudiante de derecho, la fuente del estudio de las obligaciones civiles y demás contratos era el Código Civil, texto normativo correctamente elaborado y promulgado a finales del siglo XX, específicamente en el año 1984, en un contexto ajeno a la globalización y a la economía del conocimiento que vivimos ahora, en el siglo XXI.

Posteriormente, siendo ya abogado y estudiante de maestría, el Código Civil fue modificado para incorporar la firma electrónica en los contratos.

Actualmente existen nuevas formas de transacciones económicas y comerciales entre partes contratantes cuyos nombres muchas veces se desconocen y en las que tampoco se identifica en forma tangible al objeto de acto jurídico, que, por el contrario, se expresa en forma criptográfica mediante códigos cifrados. Tales operaciones virtuales pueden funcionar regularmente, pero también hay casos en los que surge un problema de inejecución o de invalidez. Y es allí donde se plantea la siguiente pregunta a manera de reflexión: ¿cómo solucionar estas controversias en las que el agente y el objeto del negocio no están individualizados ni determinados conforme a los requisitos previstos en las reglas clásicas del derecho civil, sino que tales datos se hallan codificados en algoritmos que garantizan la confidencialidad de esta información?

Esta interrogante trae a la memoria que la ciencia del derecho mantiene su vigencia en la medida en que sea capaz de prevenir y solucionar normativamente los conflictos o las incertidumbres jurídicas que continuamente surgen dentro de la sociedad. El derecho, expresado en las leyes formales promulgadas por el Estado no es siempre eficaz frente a la dinámica continua de los conflictos sociales. Por ello, un elemento importante en las normas jurídicas es mantener su vigencia ante nuevas formas de relaciones jurídicas. Es este contexto el que me motivó a investigar un tema que suscita mucha disputa: el bitcóin.

El objetivo de este artículo científico es identificar cuál debe ser la política pública apropiada con respecto a la moneda digital bitcóin; para ello, desarrollaré un marco conceptual para lo que es el bitcóin, las bases filosóficas relacionadas con este y, finalmente, el análisis documental de jurisprudencias comparadas que han resuelto problemas o dudas sobre su empleo. 


\section{Marco conceptual del bitcóin}

El bitcóin es un método de moneda digital, esto es, una moneda no percibida físicamente, sino que circula a nivel de las redes informáticas.

Para comprender la motivación que generó la creación del bitcóin, es necesario comparar las actuales transacciones electrónicas bancarias de débito o de crédito. Tales actividades ahorran tiempo, pero conllevan una comisión que cobra el banco o la entidad financiera en desmedro del patrimonio del titular de la cuenta bancaria o financiera.

Paralelamente, existe el dinero que se utiliza materialmente en las diversas actividades económicas cotidianas. El respaldo de la moneda, sin embargo, dependerá de la estabilidad económica del Estado emisor; un ejemplo es el caso del dólar estadounidense, cuyo valor monetario frente al sol peruano sube en algunas ocasiones (depreciación del sol), mientras que en otras baja (apreciación del sol) a causa de factores políticos y sociales muchas veces imprevisibles, como ha sido la pandemia de la covid-19, por ejemplo.

Frente a los retos de los actuales medios de pago, aparece el bitcóin, moneda digital que fue creada en el año 2008 por Satoshi Nakamoto, seudónimo empleado aparentemente por un colectivo de personas de quienes hasta ahora nadie sabe el nombre exacto. Su inventor (o quienes) define(n) al bitcóin de la siguiente manera:

Hemos propuesto un sistema para transacciones electrónicas sin depender de la confianza. Empezamos con el marco habitual de monedas hechas de firmas digitales, que proporciona un fuerte control de propiedad, pero está incompleta sin una forma de evitar el doble gasto. Para solucionar esto, nosotros proponemos una red peer-to-peer usando prueba de trabajo para registrar un historial público de transacciones que rápidamente se vuelve computacionalmente impráctico para que un atacante cambie si los nodos honestos controlan la mayor parte de la potencia de la CPU ${ }^{1}$.

Conforme a la definición, la seguridad de este método digital de pago lo otorga el nodo, esto es, redes de particulares que cumplen una función fe-

1 Satoshi Nakamoto, Bitcóin: A Peer-to-Peer Electronic Cash System, acceso el 9 de marzo de 2021, https://bitcoin.org/bitcoin.pdf), p. 8. 
dataria de las operaciones digitales, lo que presenta, además, las siguientes ventajas:

- No requiere que el agente que haga las transacciones electrónicas tenga que pagar una comisión.

- Su valor no depende ni del Estado ni de una empresa privada. Su estimación está supeditada a la confianza que le han dado las personas que utilizan este método de pago en sus transacciones.

- Existe reserva sobre la identidad de los sujetos y del objeto del negocio. Lo único que hay en el método bitcóin es la certificación inmediata de toda transferencia por un grupo de usuarios — conocidos como «mineros»-, que darán fe de la transacción realizada. Por ejemplo, si una persona quiere comprar un kilo de oro y pagarlo con bitcoines, los mineros lo verifican e inmediatamente comunican a la red que se ha efectuado la transferencia mediante el registro contable digital cifrado o codificado respecto del producto comprado.

Como se ha señalado anteriormente, el interés de muchas personas por utilizar el bitcóin reside en la posibilidad de adquirir un producto sin que se sepan ni sus nombres ni el objeto de la operación realizada; en todo caso, esta confidencialidad genera mucho interés en efectuar más transacciones mediante bitcoines.

Paralelamente, existe un grupo o red de personas - los ya mencionados «mineros»- que se encargan de certificar continuamente las operaciones efectuadas mediante bitcoines. Este registro contable digital se conoce como «bloque», y para tal certificación se requiere la conformidad de todos los «mineros», quienes reciben a cambio una determinada cantidad de bitcoines; y estos, a su vez pueden ser adquiridos por los interesados en realizar transacciones con esta moneda digital. No hay un organismo regulador de dicho registro: su elaboración dependerá de la confirmación consensual de los «mineros».

Los «bloques» proporcionan seguridad sobre la existencia de las transferencias sin permitir conocer el nombre de la persona ni la prestación realizada. Este libro contable digital, sin embargo, permite verificar el movimiento contable de los bitcoines utilizados.

La confidencialidad que ofrecen las operaciones mediante bitcóin es muy controversial. Algunos consideran que estas actividades, a pesar de no estar previstas legalmente, deben ser permitidas, puesto que no constituyen propiamente actos ilícitos; otras opiniones, en cambio, sostienen que tales operaciones pueden resultar peligrosas, ya que bajo ellas se puede formar un mer- 
cado negro digital para la compra y venta de bienes ilegales. Ante tal discusión, desarrollaré las posturas filosóficas vinculadas con esta moneda digital.

\section{Marco filosófico relacionado con el bitcóin}

Existen tres concepciones filosóficas: el libertarismo, que respalda al bitcóin; el liberalismo, que lo permite; y el ordoliberalismo, que se muestra en contra del bitcóin.

\subsection{Libertarismo}

Tiene como ideal supremo el irrestricto respeto a la libertad; considera, por tanto, que la intervención estatal debe ser nula en las acciones que las personas realizan espontáneamente; rechaza todo acto del Estado que implícitamente sustituya el libre albedrío y la voluntad consciente de asumir las consecuencias de las decisiones tomadas. En materia económica, defiende que toda actividad se regule naturalmente, sin intervención de los poderes públicos. Tal regulación natural es concebida por Adam Smith como «la mano invisible»:

En la medida en que todo individuo procura en lo posible invertir su capital en la actividad nacional y orientar esa actividad para que su producción alcance el máximo valor, todo individuo necesariamente trabaja para hacer que el ingreso anual de la sociedad sea el máximo posible. Es verdad que por regla general él no intenta promover el interés general ni sabe en qué medida lo está promoviendo. Al preferir dedicarse a la actividad nacional más que a la extranjera él solo persigue su propia seguridad; y al orientar esa actividad para producir el máximo valor, él busca su propio beneficio; pero en este caso como en otros muchos, una mano invisible lo conduce a promover un objetivo que no entraba en sus propósitos. El que sea así no es necesariamente malo para la sociedad. Al perseguir su propio interés frecuentemente fomentará el de la sociedad mucho más eficazmente que si deliberadamente intentase fomentarlo².

2 Adam Smith, La riqueza de las naciones, libro IV, cap. II. Trad. por Carlos Rodríguez Braun, https:/ / www.memoriapoliticademexico.org/Textos/1Independencia/Imag/1776-AS-LRN. pdf), p. 370. 
El libertarismo cuestiona las intervenciones y restricciones estatales, por cuanto, bajo esta concepción filosófica, tales medidas paternalistas subrogan la determinación de las personas, incluso cuando responsablemente aceptan el riesgo de la decisión tomada. Ante tal consentimiento informado, resulta impertinente que un tercero — en este caso, el Estado - intervenga o restrinja la voluntad privada, tal como lo sostiene Robert Nozick:

¿Tengo en realidad que indemnizar a aquel a quien impido, en defensa propia, que juegue a la ruleta rusa conmigo? Si alguna persona desea usar un proceso muy arriesgado pero eficiente ( $\mathrm{y}$, si las cosas van bien, sin daño) para manufacturar un producto, ¿tienen que indemnizarlo los vecinos cercanos a la fábrica por la pérdida económica que sufra al no permitírsele usar un proceso posiblemente peligroso? Seguramente, no.

[...]

Todo individuo tiene, efectivamente, el derecho a una información suficiente, que muestre que un procedimiento de administración de justicia que se le va a aplicar es confiable y justo.

[...]

Cuando la información se hace pública o le es disponible, él está en posición de conocer la confiabilidad y justicia del procedimiento. Él examinará esta información y, si encuentra el sistema dentro de los límites de confiabilidad y justicia, tendrá que someterse a él ${ }^{3}$.

Conforme al pensamiento de Robert Nozick, carece de sentido la intervención estatal en las actividades de los particulares si estas fueron celebradas en forma voluntaria e informada, aun cuando pueden causar un perjuicio.

\subsection{Liberalismo}

Esta corriente filosófica proclama como valor central la libertad y, de manera conexa, defiende la propiedad privada. Uno de sus más altos representantes fue el filósofo británico John Locke, quien sostenía que la razón para la existencia de un Estado reside principalmente en proteger la propiedad privada y la libertad de sus ciudadanos sin que esto signifique una intervención estatal que compita con los particulares en la libre actividad económica:

3 Robert Nozick, Anarquía, Estado y utopía (Buenos Aires: Fondo de Cultura Económica, 1991), 88 y 107 
Para comprender adecuadamente el poder político y rastrear sus orígenes, debemos considerar el estado en el que todas las personas se encuentran naturalmente. Ese es un estado de perfecta libertad para actuar y disponer de sus propias posesiones y personas como creen que encaja dentro de los límites de la ley de la naturaleza.

Si el hombre en el estado de naturaleza es tan libre, como se ha dicho; si es señor absoluto de su propia persona y posesiones, igual al mayor y no está sujeto a nadie, ¿por qué se separará de su libertad? ¿Por qué abandonará este imperio y se someterá al dominio y control de cualquier otro poder? A lo que es obvio responder, que, aunque en el estado de naturaleza tiene tal derecho, sin embargo, el goce de él es muy incierto y constantemente expuesto a la invasión de otros: porque todos son reyes tanto como él, cada hombre su igual, y la mayor parte no estrictos observadores de la equidad y la justicia, el disfrute de la propiedad que tiene en este estado es muy inseguro, muy inseguro. Esto hace que esté dispuesto a abandonar una condición que, por libre que sea, está llena de miedos y peligros continuos: y no es sin razón, que busca y está dispuesto a unirse en sociedad con otros, que ya están unidos, o tienen la intención de unirse, para la preservación mutua de sus vidas, libertades y propiedades, a las que llamo por el nombre general, propiedad ${ }^{4}$.

Parafraseando la cita transcrita en los párrafos precedentes, la función del Estado es garantizar la eficacia del modo de producción de los privados, no modificarlo ni competir con ellos.

Aunque el libertarismo y el liberalismo tienen en común el respeto a la libertad de la persona, el elemento que distingue uno de otro es que en el primero la intervención estatal debe ser eliminada cuando los actos se desarrollan libremente; en el segundo, en cambio, existe una intervención mínima estatal que, si bien no sustituye la libertad de la persona, es necesaria para ga-

4 John Locke, Two treatises on Government: A Translation into modern english (Industrial Systems Research, 2019, https://books.google.com.pe/books?id=d_4BGe7-pFIC\&q=\%2 $2 \mathrm{To}+$ properly+understand+political+power+and+trace+its+origins,$+\mathrm{we}+$ must + consider+the+state+that+all+people+are+in+naturally.+That+is+a+state+of+perfect+freedom+of+acting+and+disposing+of+their+own+possessions+and+persons+as+they+think+fit + within + the +bounds\&pg $=$ PA $106 \&$ redir_esc $=y \# v=$ snippet \& $q=\% 22$ To $\% 20$ properly $\% 20$ understand $\% 20$ political $\% 20$ power $\% 20$ and $\% 20$ trace $\% 20$ its $\% 20$ origins $\% 2 C \% 20$ we $\% 20$ must $\% 20$ consider $\% 20$ the $\% 20$ state $\% 20$ that $\% 20$ all $\% 20$ people $\% 20$ are $\% 20$ in $\% 20$ naturally. $\% 20$ That $\% 20$ is $\% 20$ a $\% 20$ state $\% 20$ of $\% 20$ perfect $\% 20$ freedom $\% 20$ of $\% 20$ acting $\% 20$ and $\% 20$ disposing $\% 20$ of $\% 20$ their $\% 20$ own $\% 20$ possessions $\% 20$ and $\% 20$ persons $\% 20$ as $\% 20$ they $\% 20$ think\%20fit $\% 20$ within $\% 20$ the $\% 20$ bounds\&f=false 
rantizar el cumplimiento de las actividades, transacciones o compensaciones que correspondan.

\subsection{Ordoliberalismo}

Esta escuela defiende una postura intermedia frente a cualquier radicalismo en lo que se refiere tanto a la libertad como al intervencionismo estatal. Bajo esta concepción, se respeta la libertad de la persona en la medida en que no represente una amenaza para los intereses comunes de la sociedad. En otras palabras, se promueve el desarrollo, según Alfred Mueller-Armack, «en base a una economía de competencia vincular la libre iniciativa con un progreso social garantizado por los rendimientos de la economía de mercado» ${ }^{5}$.

Dentro de este marco, si bien se respeta la libertad de transacción de los particulares, también es cierto que esta debe someterse a un fin social, y en ese sentido el papel del Estado es, además de garantizar la libertad de los particulares, regular las actividades privadas a fin de prevenir cualquier abuso que afecte los intereses de la colectividad.

\subsection{Vinculación del libertarismo, liberalismo y ordoliberalismo con el bitcóin}

Bajo el libertarismo, el bitcóin debe ser respetado, y el Estado debe mantenerse aislado de cualquier intento de intervención, atendiendo que la aceptación de esta moneda digital es la expresión de una decisión libre de realizar operaciones que no sean respaldadas por ningún Estado, a pesar de que esto pueda constituir un riesgo patrimonial.

Por su parte, el liberalismo también defiende que la política pública no debe enfocarse en constituir organismos públicos reguladores, pero sí considera necesaria la existencia de mecanismos legales que tutelen el cumplimiento de las transacciones y eviten cualquier fraude.

Finalmente, el ordoliberalismo, aunque respeta el bitcóin, justifica que las operaciones realizadas en dicha moneda digital deben ser reguladas y super-

5 Eugenio Mario Recio, «La democracia cristiana y la economía social», La Factoría 27, mayo-agosto (2005), https: / / lafactoriaweb.com/recio26 
visadas por el Estado para evitar actos que afecten el orden económico y financiero de la nación.

\section{Marco metodológico}

El objetivo de la presente investigación es identificar cuál debe ser la política pública apropiada con respecto al bitcóin. Según el problema formulado, se plantean dos hipótesis que buscan resolver tal interrogante:

- Hipótesis principal: la política pública debe regular las operaciones realizadas en bitcoines.

- Hipótesis nula: la política pública no debe regular las operaciones realizadas en bitcoines.

La variable de la hipótesis por contrastar es «política pública regulatoria». Dicha variable es cualitativa y se define como el conjunto de decisiones gubernamentales que previenen, protegen o castigan cualquier daño o controversia relacionados con operaciones que se realicen utilizando bitcoines. Por ende, los indicadores que identifican tal variable son las siguientes:

- Supervisión

- Fiscalización

- Sanción

- Resolución de disputas

- Expedición de medidas preventivas.

Si en la etapa de comprobación de hipótesis no se verifica la existencia de todos los indicadores mencionados, entonces, por descarte, quedará demostrada la hipótesis nula.

La investigación empleada será básica y práctica, esto es, los fundamentos de casos resueltos relacionados con el bitcóin se examinarán dentro de la jurisprudencia comparada y se identificará cuál es el marco filosófico aplicable a las transacciones con esta moneda digital.

El diseño de investigación no será experimental, porque solo se recopilarán los fundamentos de las resoluciones expedidas por los tribunales de justicia; la muestra empleada será no probabilística, ya que la información recogida en estos materiales responde a los criterios personales de los jueces, los cuales no constituyen datos objetivos o cuantificables, sino subjetivos o cualitativos. 
Asimismo, el diseño de investigación es transeccional o transversal, es decir, las resoluciones que constituyen materia de análisis son datos que se han recogido sin evaluar su evolución en el tiempo.

Asimismo, se utilizará como técnica de investigación el análisis documental, en la que se recurrirá a la jurisprudencia comparada. Y se aplicará un método de análisis deductivo; es decir, a partir de casos específicos resueltos por los tribunales en cuestión, se identificarán criterios generales aplicables para una propuesta de política pública.

La limitación que presenta este trabajo es la escasez de controversias sobre bitcóin resueltas. Por ello se ha recurrido a la jurisprudencia comparada.

\section{Resultado y discusión de la jurisprudencia comparada}

Como se señaló anteriormente, se comprobará la hipótesis analizando la jurisprudencia comparada, identificando los resultados o hallazgos encontrados, así como mediante su interpretación o discusión. Para ello, transcribiré como resultados los fundamentos de las resoluciones halladas que sean pertinentes para el problema de investigación científica y, seguidamente, procederé a su respectiva discusión.

\subsection{Resultado n. ${ }^{\circ} 1$}

Tribunal de Justicia de la Unión Europea (Sala Quinta). Asunto C-264/14. Fecha de publicación: 22 de octubre de 2015. Consultado el 5 de marzo de 2021 en http://curia.europa.eu/juris/document/document.jsf?docid=170305\&doclang $=\mathrm{ES}$

\section{Antecedentes}

La petición de decisión prejudicial tiene por objeto la interpretación de los artículos 2, apartado 1, y 135, apartado 1, de la Directiva 2006/112/CE del Consejo, de 28 de noviembre de 2006, relativa al sistema común del impuesto sobre el valor añadido (DO L 347, p. 1; en lo sucesivo, «Directiva del IVA»).

Dicha petición se planteó en un litigio entre el Skatteverket (Administración Tributaria Sueca) y el señor Hedqvist, en relación con un dictamen previo 
emitido por la Skatterättsnämnden (Comisión de Derecho Fiscal) sobre la sujeción al impuesto del valor añadido de las operaciones de cambio de divisas tradicionales por la divisa virtual «bitcoin», o viceversa, que el señor Hedqvist desea realizar por medio de una sociedad.

Sobre las cuestiones prejudiciales

52. En el litigio principal, consta que la divisa virtual «bitcoin» no tiene ninguna finalidad distinta de la de ser un medio de pago y que ciertos operadores la aceptan como tal.

53. En consecuencia, procede concluir que el artículo 135, apartado 1, letra e), de la Directiva del IVA se refiere igualmente a unas prestaciones de servicios como las controvertidas en el litigio principal, consistentes en un intercambio de divisas tradicionales por unidades de la divisa virtual «bitcoin», y viceversa, y realizadas a cambio del pago de un importe equivalente al margen constituido por la diferencia entre, por una parte, el precio al que el operador de que se trate compre las divisas y, por otra, el precio al que las venda a sus clientes.

54. En lo que respecta, por último, a las exenciones establecidas en el artículo 135, apartado 1, letra f), de la Directiva del IVA, basta con recordar que esta disposición menciona, en particular, las operaciones relativas a «acciones, participaciones en sociedades o asociaciones [y] obligaciones», a saber, títulos que confieren un derecho de propiedad sobre personas jurídicas, y las operaciones relativas a los «demás títulos-valores», de los que debe considerarse que tienen una naturaleza comparable a la de los títulos-valores específicamente mencionados en dicha disposición (sentencia Granton Advertising, C461/12, EU:C:2014:1745, apartado 27).

55. Pues bien, consta que la divisa virtual «bitcoin» no es ni un título que confiera un derecho de propiedad sobre personas jurídicas ni un título que tenga una naturaleza comparable.

56. Por consiguiente, las operaciones controvertidas en el litigio principal no están incluidas en el ámbito de aplicación de las exenciones establecidas en el artículo 135, apartado 1, letra f), de la Directiva del IVA.

[...]

En virtud de todo lo expuesto, el Tribunal de Justicia (Sala Quinta) declara: 1) El artículo 2, apartado 1, letra c), de la Directiva 2006/112/CE del Consejo, de 28 de noviembre de 2006, relativa al sistema común del impuesto sobre el valor añadido, debe interpretarse en el sentido de que constituyen prestaciones de servicios realizadas a título oneroso, en el sentido de esta disposición, unas operaciones como las controvertidas en el litigio principal, consistentes en un intercambio de divisas tradicionales por unidades de la divisa virtual «bitcoin», y viceversa, y realizadas a cambio del pago de un importe equivalente al margen constituido por la 
diferencia entre, por una parte, el precio al que el operador de que se trate compre las divisas y, por otra, el precio al que las venda a sus clientes.

$[\ldots]$

\section{Discusión del resultado $n .^{\circ} 1$}

La controversia por dilucidar era si las operaciones realizadas con bitcoines constituían objeto de tributación. Al respecto, el Tribunal de Justicia de la Unión Europea reconoce que son instrumentos de pago por prestaciones realizadas a título oneroso y, como tal, pasibles de obligaciones legales, como lo es el impuesto al valor agregado.

De este precedente se deduce que al ser controversias surgidas por operaciones realizadas con unidades digitales de bitcóin pueden ser resueltas por el Estado. Sin embargo, en dicha sentencia no existe fundamentación que contemple la necesidad de algún órgano público regulador que sancione, supervise o fiscalice las transacciones realizadas mediante bitcóin.

\subsection{Resultado n. ${ }^{\circ} 2$}

Cámara Federal de San Martín, Sala I, c. 7130/2017/34/CA5 «R. C., Max y otros s / legajo de apelación», Argentina. Fecha de publicación: 28 de noviembre de 2017. Consultado el 5 de marzo de 2021 en https:/ / derechopenalonline.com/caso-bobinas-blancas-lavado-de-activos-de-origen-ilegal-monedas-virtuales-intercambiador-de-bitcoins-procesamiento /

\section{Antecedentes}

El caso llegó a conocimiento del Tribunal con motivo de los recursos de apelación contra la resolución que decreta los procesamientos de diversas personas, entre ellas de Emmanuel G., como prima facie autor del delito de lavado de activos de origen ilegal.

La defensa de Emmanuel G. invocó que la acción atribuida a su asistido resultaba atípica, en tanto consideró que «la operación que se le cuestiona no ha significado ni perseguido transmitirle apariencia lícita a las sumas de dinero que entregó en la operación de compraventa de bitcoins». Resaltó que, dada la ausencia de regulación específica, no puede calificarse como ilegal «una operación empleando bitcoins». Señaló, igualmente, que el dinero debía 
ser de origen ilegal y que ello no se había establecido, en tanto que «se trata de sumas de dinero ingresadas mediante una operación no regulada legalmente» y destacó que «la prueba sobre la ilicitud de las sumas de dinero no está dada en el origen de los fondos sino en su destino para el contrabando investigado y frustrado, cuestión ajena a G.».

\section{VISTOS y CONSIDERANDO: \\ III}

$[\ldots]$

Situación de Emmanuel G

\section{$[\ldots]$}

El protocolo de Bitcoin no requiere o proporciona la identificación y verificación de los participantes o genera registros históricos de las transacciones que están necesariamente asociadas con la identidad del mundo real. No hay ningún órgano de supervisión central y no hay software de ALA (Antilavado de Activos) disponible actualmente para monitorear e identificar patrones de transacciones sospechosas. Las agencias de orden público no pueden apuntar a una ubicación o entidad central (administrador) para fines investigativos o de incautación de activos (aunque las autoridades pueden apuntar a cambiadores individuales para la información del cliente que puede recopilar el cambiador). Por lo tanto, ofrece un nivel de potencial anonimato imposible con tarjetas de crédito y débito tradicionales o sistemas de pago en línea más viejos, tales como PayPal.

El alcance global de la moneda virtual al igual aumenta sus potenciales riesgos de ALA/CFT (Antilavado de Activos / Contra el Financiamiento del Terrorismo). Los sistemas de moneda virtual pueden ser accedidos a través del Internet (incluso a través de los teléfonos móviles) y pueden ser utilizados para hacer los pagos transfronterizos y transferencias de fondos. Además, las monedas virtuales comúnmente dependen de infraestructuras complejas que involucran a varias entidades, a menudo repartidas en varios países, para transferir fondos o ejecutar los pagos. Esta segmentación de servicios significa que la responsabilidad de cumplimiento ALA/CFT y supervisión/ejecución puede ser confusa. Por otra parte, los registros de clientes y transacciones podrán estar en manos de distintas entidades, a menudo en jurisdicciones diferentes, lo que dificulta a las agencias de orden público y los reguladores accederlos.

Este problema es exacerbado por la naturaleza rápidamente cambiante de la tecnología de moneda virtual descentralizada y modelos de negocio, incluyendo los cambios de número y tipos/los roles de los participantes que proporcionan servicios en sistemas de pago de moneda virtual. Y, sobre todo, los componentes 
de un sistema de moneda virtual pueden estar ubicados en jurisdicciones que no cuentan con adecuados controles de ALA/CFT.

Sistemas de moneda virtual centralizada podrían ser cómplices en el lavado de activos y podrían buscar deliberadamente a jurisdicciones con regímenes débiles de ALA/CFT. Las monedas virtuales convertibles descentralizadas que permiten transacciones de persona a persona de manera anónima parecen existir en un universo digital totalmente fuera del alcance de cualquier país en particular. $[\ldots]$

Más allá de que efectivamente su actividad no se encuentre regulada, ello no parece a esta altura como una condición que obstruya verificar que su conducta consistió en ingresar, dentro del circuito económico local, dinero del exterior que, es evidente, no aparece como viable de haber sido fácilmente introducido por los canales legales, sin que implicara "un [sic] alerta de operación sospechosa", con las exigencias que ello conlleva. La magnitud de las transacciones que, se insiste, una persona desconocida para el "intercambiador", depositó en confianza en un tercero al que, tampoco conocían los "usuarios", todo amparado por el anonimato de los participantes de las transacciones, constituye un indicio vehemente de que se trataba de dinero de origen no legal.

\section{Discusión del resultado n. ${ }^{\circ} 2$}

La controversia del presente caso era si la transacción podría ser considerada herramienta para la comisión del delito de lavado de activos.

La resolución expedida por el tribunal de justicia argentino en cuestión advierte que, dada la falta de un órgano rector regulador, las operaciones realizadas en moneda digital pueden constituir indicios reveladores del ingreso de dinero de origen ilegal; y que se justifica un proceso judicial para deslindar lavado de activos o financiamiento del terrorismo.

En sus considerandos, a pesar de mostrar preocupación por la moneda digital a causa de la inexistencia de un ente rector centralizado, de dicho precedente jurisdiccional no se desprende, sin embargo, que cuestione la invalidez absoluta de este método de pago ni mucho menos exija una fiscalización estatal, sanción o medida preventiva contra él. Se concentra, en cambio, en que el Estado asuma su rol de investigación con respecto a la probable conducta dolosa o animus de la persona para utilizar como instrumento de pago el bitcóin. 


\subsection{Resultado . $^{\circ} 3$}

El Estado de Florida, Apelante, vs. Michell Espinoza, Apelado. Tribunal de Apelaciones del Tercer Distrito del Estado de Florida. Fecha de publicación: 30 de enero de 2019, consultado el 05 de marzo de 2021 en https:/ / casetext.com/ case/state-v-espinoza-53

\section{Antecedentes}

Se le imputa al acusado actuar ilegalmente como vendedor de instrumentos de pago o participar en el negocio de un transmisor de dinero, funciones ambas para las que se requiere, según la ley del Estado de Florida, registrarse como un negocio de servicios monetarios.

El acusado no discute el hecho de no contar con licencia para actuar como empresa de servicios monetarios en el Estado de Florida. Más bien, sobre la base de que el bitcóin no es «dinero» o «valor monetario» para los propósitos de los estatutos que rigen las empresas de servicios monetarios, sostiene que sus transacciones no califican como tales.

\section{Análisis del Tribunal de Apelación}

[...]

No hay duda de que Bitcoin no se incluye expresamente en la definición de "moneda" que se encuentra en la sección 560.103 (11). Sin embargo, Bitcoin entra dentro de la definición de "instrumento de pago". Ver § 560.103 (29). En la definición de instrumento de pago se incluye el "valor monetario", que se define como "un medio de cambio, reembolsable o no en moneda". §§ 560.103 (21), (29). De acuerdo con la declaración jurada de arresto y el Informe de moneda virtual del GAFI, mencionado anteriormente, los bitcoins se pueden canjear por moneda. Espinoza no argumenta lo contrario. De manera similar, Bitcoin y bitcoins funcionan como un "medio de intercambio". Ver $§ 560.103$ (21).

Además de afirmar que no es un vendedor de instrumentos de pago, Espinoza afirma que Bitcoin no califica como "dinero" o "valor monetario" a los efectos de ser un "transmisor de dinero". Argumenta que la Legislatura de Florida no podría haber contemplado la aplicación de la sección 560.125 a las monedas virtuales cuando se promulgó el estatuto. Como tal, Bitcoin no puede considerarse moneda porque no es moneda de curso legal sobre la base de que los términos "dinero" y "valor monetario" se consideran sinónimos del término "moneda". No son. 
Sin embargo, no necesitamos considerar la intención legislativa porque la sección 560.103 es clara e inequívoca. Cualquier afirmación de que "valor monetario" es sinónimo de "moneda" pasa por alto el lenguaje expreso contenido en la sección 560.103 (21) que establece que el valor monetario es "un medio de cambio, sea o no canjeable en moneda". La interpretación de Espinoza pasa por alto el "principio legal de que los tribunales deben evitar lecturas que dejarían sin sentido parte de una ley". Koile v. State, 934 So.2d 1226, 1233 (Fla.2006) (citando Forsythe v. Longboat Key Beach Erosion Control Dist. , 604 So.2d 452, 456 (Fla. 1992). Además, la interpretación de Espinoza, que nos negamos a adoptar, obligando a que "valor monetario" sea sinónimo de "moneda", dejaría sin sentido la sección 560.103 .

\section{Discusión del resultado n. ${ }^{\circ} 3$}

La discusión era si con las operaciones efectuadas con bitcoines, el acusado era responsable de actividades monetarias realizadas sin licencia legal.

La sentencia del tribunal de justicia estadounidense reconoce que el bitcóin también expresa un medio de cambio monetario y, como tal, genera relaciones jurídicas que pueden ser competencia de instancias jurisdiccionales estatales, sin que este reconocimiento legal implique la necesidad de que el Estado fiscalice o supervise estas operaciones. Más bien, como en el precedente judicial argentino, el Estado solo es competente para juzgar la conducta de las personas que utilizan esta moneda criptográfica sin contar con las autorizaciones legales de funcionamiento pertinentes.

\subsection{Resultado n. ${ }^{\circ} 4$}

Tribunal Supremo Sala de lo Penal. Sentencia n. ${ }^{\circ}$ 326/2019, Recurso Casación/998/2018, España. Fecha de publicación: 20 de junio de 2019. Consultado el 5 de marzo de 2021 en https:/ /jurisprudenciaderechocomercial.blogspot.com/2019/

\section{Antecedentes}

El acusado A fue condenado como autor criminalmente responsable de un delito continuado de estafa, a las penas de dos años de prisión e inhabilitación especial para el ejercicio del derecho de sufragio pasivo durante el tiempo de la condena; debía además abonar las costas procesales, con inclusión de los honorarios de la acusación particular. Asimismo, se ordenó al acusado indem- 
nizar a Y., a M., a J., a O. y a S., por el valor de la cotización del bitcóin en el momento de la finalización de cada uno de sus respectivos contratos, que se determine en ejecución de sentencia, con el interés legal previsto en el art. 576 LEC (Ley de Enjuiciamiento Civil).

La representación de M., S., Ó., Y. y J., formulan un único motivo de casación por infracción de ley, al amparo del artículo 849.1 de la LECRIM (Ley de Enjuiciamiento Criminal), al entender indebidamente aplicados los artículos 110 y 11 del Código Penal de España. El alegato sostiene que los artículos 110 y 111 del Código Penal obligan a la restitución de la cosa en el mismo bien; por esta razón, lo procedente sería que la sentencia condenara al acusado a restituir los bitcoines sustraídos y, solo si en fase de ejecución de sentencia no se restituyeren esos bienes, proceder entonces a su valoración y a acordar la devolución de su importe.

Fundamentos de derecho:

[...]

Tercero:

$[\ldots]$

Aun cuando la jurisprudencia de esta Sala ha expresado la obligación de restituir cualquier bien objeto del delito, incluso el dinero, los acusados no fueron despojados de bitcoins que deban serles retornados, sino que el acto de disposición patrimonial que debe resarcirse se materializó sobre el dinero en euros que, por el engaño inherente a la estafa, entregaron al acusado para invertir en activos de este tipo. Por otro lado, tampoco el denominado bitcoin es algo susceptible de retorno, puesto que no se trata de un objeto material, ni tiene la consideración legal de dinero.

$[\ldots]$

De este modo, por más que la prueba justificara que el contrato de inversión se hubiera hecho entregando los recurrentes bitcoins y no los euros que transfirieron al acusado, el Tribunal de instancia no puede acordar la restitución de los bitcoins, siendo lo adecuado reparar el daño e indemnizar los perjuicios en la forma que se indicó en la sentencia de instancia, esto es, retornado a los perjudicados el importe de la aportación dineraria realizada (daño), con un incremento como perjuicio que concreta en la rentabilidad que hubiera ofrecido el precio de las unidades bitcoin entre el momento de la inversión y la fecha del vencimiento de sus respectivos contratos. 


\section{Discusión del resultado $n .{ }^{\circ} 4$}

La controversia del caso era cómo la justicia debía resarcir el daño ocasionado por fraude en inversiones mediante operaciones con moneda digital.

Si bien el tribunal supremo español asume en la sentencia que es competente para resolver jurisdiccionalmente la controversia de reparación del daño causado por el fraude de inversión por bitcóin, también es cierto que la resolución delimita que la reparación de los daños producidos por el uso de la mencionada moneda digital solo debe indemnizarse en euros.

La orden de resarcir a la víctima con la entrega de euros evita que los jueces intervengan internamente en el manejo contable del bitcóin, ya que este tiene sus propias reglas de transferencias y de registro, a través de los llamados «mineros», a las que el Estado debe permanecer ajeno.

\section{Conclusiones}

En mérito del análisis de los precedentes jurisdiccionales, se llega a las siguientes conclusiones:

- Queda comprobada la hipótesis principal, es decir, la política pública debe regular las operaciones realizadas en bitcoines. Sin embargo, tal regulación se restringe a solucionar disputas relacionadas con tales transacciones sin que el Estado supervise, fiscalice, castigue o imponga medidas preventivas contra estas. Se aclara que tales decisiones estatales no deben interferir en el manejo contable digital de las operaciones con bitcóin.

- Al comprobarse que la política pública se limita a solucionar disputas, se advierte que la jurisprudencia comparada adopta específicamente la escuela liberal y no el libertarismo, esto es, que se debe respetar la plena libertad de contratación mediante moneda criptográfica y solo se puede recurrir al Estado en el caso que se necesite resolver disputas, sin interferir en el registro contable digital que utilice el bitcóin.

- Queda descartada la hipótesis nula, esto es, se rechaza que la política pública no deba regular las operaciones realizadas por bitcóin. Por ende, se desecha que en operaciones por bitcóin sea aplicable el ordoliberalismo. 


\section{Referencias}

Locke, John. Two treatises on Government:ATranslationinto Modern English. Industrial Systes Research, 2019. https://books.google.com.pe/books?id=d_4BGe7-pFIC\&$\mathrm{q}=\% 22 \mathrm{To}+$ properly+understand + political + power+and+trace+its+origins, +we+must+consider+the+state+that+all+people+are+in+naturally.+That + is $+a+s-$ tate+of+perfect+freedom +of+acting+and+disposing +of+their+own+possessions+and+persons+as+they+think+fit+within+the+bounds\&pg=PA106\&redir_esc $=y \# \mathrm{v}=$ snippet\&q= $\% 22 \mathrm{To} \% 20$ properly $\% 20$ understand $\% 20$ political $\% 20$ power $\% 20$ and $\% 20$ trace $\% 20$ its $\% 20$ origins $\% 2$ C $\% 20$ we $\% 20$ must $\% 20$ consider $\% 20$ the $\% 20$ state $\% 20$ that $\% 20$ all $\% 20$ people $\% 20$ are $\% 20$ in $\% 20$ naturally. $\% 20$ That $\% 20$ is $\% 20$ a $\% 20$ state $\% 20$ of $\% 20$ perfect $\% 20$ freedom $\% 20$ of $\% 20$ acting $\% 20$ and $\% 20$ disposing $\% 20$ of $\% 20$ their $\% 20$ own $\% 20$ possessions $\% 20$ and $\% 20$ persons $\% 20$ as $\% 20$ they $\% 20$ think $\% 20$ fit $\% 20$ within $\% 20$ the $\% 20$ bounds\&f=false

Nakamoto, Satoshi. Bitcoin: A Peer-to-Peer Electronic Cash System. Acceso el 9 de marzo de 2021. https: / / bitcoin.org/bitcóin.pdf

Nozick, Robert. Anarquía, Estado y utopía. Buenos Aires: Fondo de Cultura Económica, 1991.

Recio, Eugenio Mario. «La democracia cristiana y la economía social». La Factoría 27 (2005). https:/ / lafactoriaweb.com/recio26

Smith, Adam. La riqueza de las naciones, libro IV, cap. II. Traducido por Carlos Rodríguez Braun. https://www.memoriapoliticademexico.org/Textos/1Independencia/Imag/1776-AS-LRN.pdf

Sobre el autor

Doctor en Derecho por la Universidad de San Martín de Porres, maestro en Derecho Civil por la Universidad Nacional Federico Villarreal, y abogado, aprobado por unanimidad y con mención de felicitación, por la Universidad de San Martín de Porres. Docente universitario de pregrado y posgrado en diversas universidades privadas y nacionales peruanas. 